Revista Destaques Acadêmicos, Lajeado, v. 11, n. 2, 2019. ISSN 2176-3070

DOI: http://dx.doi.org/10.22410/issn.2176-3070.v11i2a2019.2271

http://www.univates.br/revistas

\title{
O EXTRATIVISMO COMO ELEMENTO DE DESENVOLVIMENTO E SUSTENTABILIDADE NA AMAZÔNIA: UM ESTUDO A PARTIR DAS COMUNIDADES COLETORAS DE CASTANHA-DO-BRASIL EM TEFÉ, AM
}

\author{
Lindomar De Jesus de Sousa Silva ${ }^{1}$, Gilmar Antonio Meneghetti², \\ José Olenilson Costa Pinheiro ${ }^{3}$, Endrio Morais dos Santos ${ }^{4}$, \\ Daiana Matos Parintins ${ }^{5}$
}

\begin{abstract}
Resumo: A pesquisa teve como objetivo analisar os fatores socioeconômicos que contribuem para a manutenção da situação de pobreza das comunidades extrativistas e do papel dos atravessadores e comerciantes nesse processo. Foi desenvolvida em quatro comunidades extrativistas de castanha-do-brasil, no município de Tefé, AM: Caiambé, Santo Isidoro, Justiça e Marajó. A metodologia utilizada faz uma abordagem qualitativa e quantitativa do problema e busca estabelecer comparações, relações causais e inferir resultados, a partir de uma amostra estatística de $20 \%$ dos extrativistas das comunidades, num total de 31 pessoas. A investigação pode ser classificada também como exploratória, já que há poucos conhecimentos acumulados sobre essa abordagem e foi precedida de um levantamento bibliográfico, com posterior realização de entrevista semiestruturada. A pesquisa mostrou que a coleta de castanha-do-brasil pode ser um elemento que contribui para o rompimento do ciclo da pobreza e desenvolvimento nas comunidades. Para isso é preciso uma nova organização social das comunidades, capaz de se apropriar da riqueza, que é a castanha, agregando valor, mudando a forma atual de comercialização, aumentando a renda das famílias, contribuindo para a permanência dos jovens nas comunidades.
\end{abstract}

Palavras-chave: castanha-do-brasil, extrativismo, desenvolvimento, comunidades.

1 D.Sc. em Desenvolvimento Sustentável do Trópico Úmido, pesquisador da Embrapa Amazônia Ocidental, Manaus, AM.

2 Agronomo Mestre.

3 Economista, mestre.

4 Aluno da Universidade Federal do Amazonas e Bolsista de Iniciação Científica, Paic/Fapeam/ Embrapa Amazônia Ocidental, Manaus, AM.

5 Bolsista de Iniciação Científica, Paic/Fapeam/Embrapa Amazônia Ocidental, Manaus, AM. 


\section{INTRODUÇÃO}

O extrativismo é uma atividade praticada na Amazônia desde a era précolombiana. Até a chegada dos colonizadores tinha função de alimentação e de atender as necessidades das comunidades de povos nativos. Com a chegada dos colonizadores europeus, os produtos da floresta passaram ter um valor econômico alto e a fazer parte do comércio mundial. Tornaram-se importante fonte de riqueza, capaz de gerar divisas econômicas para as metrópoles de onde eram originários os exploradores.

Com o início do processo de colonização, os portugueses passaram a organizar o território, estabelecer alianças com as comunidades indígenas e povoar regiões com perspectiva de exploração, visando à obtenção dos produtos exóticos da floresta, com demanda crescente no mercado europeu.

A perspectiva econômica da colonização fez com que o desenvolvimento da região amazônica passasse a ser "moldado por ciclos de prosperidade e de recessão econômica, sempre vinculada à exploração de algum recurso natural" (GOMES, 2018, p.130).

Entre os produtos demandados pelo mercado europeu estava a castanhado- brasil. Um dos mais antigos relatos de exploração comercial da Amazônia foi feito no século XVII por Cristóvão de Lisboa, frei franciscano. O relato é rico em detalhes, com descrição dos aspectos botânicos, produtivos e do sabor do fruto da castanheira (MÜLLER et al., 2010).

A descrição do fruto da castanheira pelo padre e por viajantes mostra que a castanha-do-brasil já era explorada e comercializada antes mesmo do século XVII, quando a espécie passou "erroneamente" a ser "associada ao período de extração das drogas do sertão, nos séculos XVII e XVIII, juntamente com o cacau, a salsaparrilha, o cravo, a canela, o óleo de copaíba, entre outros" (ALMEIDA, 2016, p.1).

A importância da castanha-do-brasil no comércio extrativista vem de longa data e era praticada por diversos grupos de comerciantes da região. Os estudos de Almeida (2016) mostram que, no século XVIII, o anúncio do jornal inglês Hampshire Chronicle, de 16 de abril de 1796, já oferecia a castanha produzida na Amazônia, conhecida como Brazil nut. ${ }^{6}$ Entretanto, somente a partir de 1920, é que a castanha-do-brasil passou a ser o principal produto extrativista da Amazônia, permanecendo até os dias atuais (SANTOS, 1980). $\mathrm{Na}$ atualidade a castanha-do-brasil é um produto demandado pela indústria de alimento, farmacêutica e de cosméticos. A coleta da castanha é uma atividade defendida por organizações de defesa do meio ambiente, por ser considerada

6 Para Almeida (2016, p.6), tudo indica que foram os ingleses os primeiros a designar o nome por que a castanha-do-brasil é conhecida no mercado mundial: "Ao que parece, coube aos ingleses estabelecer a designação pela qual, até hoje, o produto é conhecido no exterior". 
essencial para manutenção e conservação da floresta e por gerar renda para as comunidades tradicionais.

A grande demanda do mercado para o produto não induz a um processo de desenvolvimento e bem-estar para as comunidades e famílias de extrativistas, que vivem em localidades distantes na Amazônia. Além de alijadas das políticas públicas, as comunidades se apropriam de forma parcial do valor da produção da castanha colhida. Atravessadores e grandes empresas compradoras ficam com valor considerável da produção. Esses fatores contribuem para a perpetuação de um quadro de pobreza das comunidades coletoras nos castanhais do estado do Amazonas.

Este artigo tem como objetivo apresentar os fatores socioeconômicos que contribuem para a manutenção da exploração das comunidades extrativistas pelos atravessadores e comerciantes, outrora conhecidos como patrões. A pesquisa foi realizada em quatro comunidades coletoras de castanha-do-brasil, no município de Tefé, AM: Caiambé, Santo Isidoro, Justiça e Marajó. Tefé está entre os dez maiores produtores de castanha-do-brasil do Amazonas.

Adotou-se uma abordagem metodológica quantitativa e qualitativa, com revisão bibliográfica sobre o tema. A coleta das informações foi realizada através de entrevistas, com aplicação de questionários, com questões semiestruturadas, para 20\% dos comunitários coletores de castanha-do-brasil.

Os resultados mostram a importância das políticas de fortalecimento do extrativismo, do crédito, da extensão rural, da comercialização e inovação tecnológica. Mostram a fragilidade organizativa das comunidades que facilita a exploração dos extrativistas pelos comerciantes e atravessadores, que se beneficiam do trabalho e dos ganhos na comercialização de castanha-do-brasil, em detrimento dos extrativistas.

\section{COLETA E COMERCIALIZAÇÃO DE CASTANHA-DO-BRASIL NO DECORRER DA HISTÓRIA}

Almeida (2016, p.4), em seus estudos históricos, mostra que a castanhado-brasil já circulava no mercado europeu desde 1633, quando os holandeses levaram um "carregamento de frutas selvagens" da Amazônia para a Holanda, que segundo Frederic Rosengarten, nesse carregamento, "provavelmente", existia "certa quantidade de castanhas (ROSENGARTEN, 1984)". Entre 1774 e 1975, a castanha-do-brasil aparece nos "relatos da viagem realizada pelo ouvidor Francisco Xavier Ribeiro de Sampaio à Capitania de São José do Rio Negro (atual estado do Amazonas)", na relação "dos produtos colhidos pelos moradores da Capitania."

Com a abertura dos portos em 1808, a castanha-do-brasil chegou ao mercado da América do Norte, "fato comprovado também através de anúncios em jornais norte-americanos no início da década de 1820", porém "Frederic 
Rosengarten aponta que o carregamento mais antigo de castanhas para os Estados Unidos foi efetuado em 1810" (ALMEIDA, 2016, p.6).

No século XIX, a castanha-do-brasil oriunda da região amazônica fez com que o Brasil passasse a ser o principal exportador mundial da amêndoa. Carvalho et al. (1993, p.5) aponta que $80 \%$ da produção de castanha-dobrasil destinava-se aos Estados Unidos, à Inglaterra e Alemanha, e os 20\% restantes a "mercados que absorviam pequenas quantidades do produto, além de apresentarem um quadro de grande rotatividade entre os próprios mercados". Brose (2016, p.79) diz que a castanha é um produto presente em diversas datas comemorativas e feriados nos países importadores, como "Natal e Ação de Graças (EUA e Reino Unido), em um nicho de alto valor agregado no processamento em chocolate e doces (Holanda, Alemanha e Itália). O autor estima que o mercado da amêndoa amazônica gire na "ordem de USD 150 milhões/ano".

Homma (2017, p.1) estima que "no apogeu da coleta expedicionária da castanha, a área foi de aproximadamente 1,5 milhão de hectares, produzindo um total de 54 milhões de litros ou aproximadamente 34 mil toneladas de castanha com casca". Esses números mostram a grande contribuição da produção de comunidades e extrativistas para o comércio mundial, já que até hoje os principais produtores de amêndoa são os castanhais nativos, distribuídos pela região Norte, como pode ser observado na Figura 1.

Figura 1. Mapa da ocorrência de castanhais nativos na Amazônia Legal Brasileira.

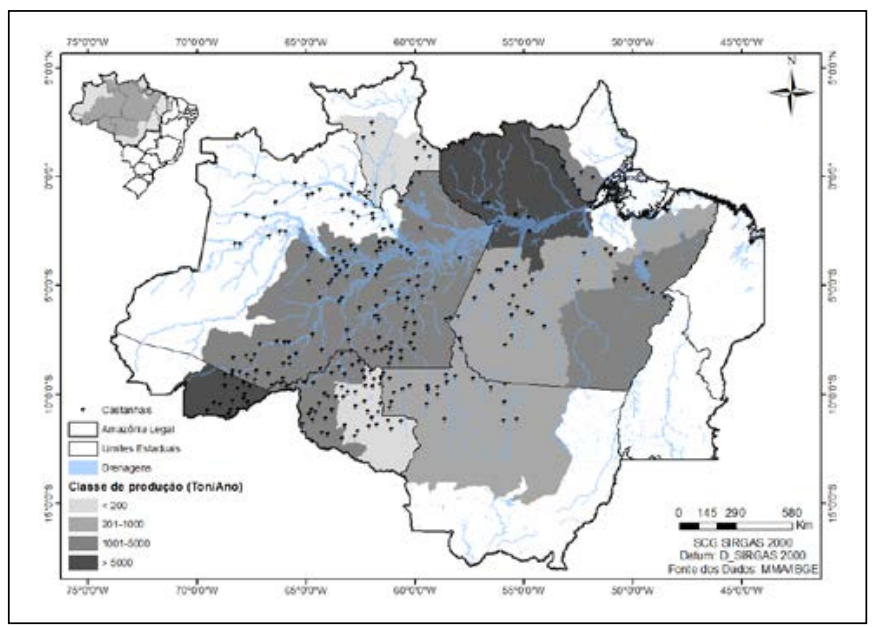

Fonte: Sousa (2018, p.162).

$\mathrm{Na}$ região Norte todos os estados produzem castanha-do-brasil e respondem por $100 \%$ da produção nacional. No período de 2010 a 2016 foram 
produzidas 272.420 toneladas. Os estados com maior produção foram o Acre e o Amazonas, que juntos respondem por mais de $60 \%$ da produção nacional, como pode ser observado no Quadro 1.

Quadro 1. Produção de castanha-do-brasil na região Norte de 2010-2016 (t).

\begin{tabular}{|c|c|c|c|c|c|c|c|c|c|c|c|c|c|c|}
\hline & \multicolumn{2}{|l|}{2011} & \multicolumn{2}{|l|}{2012} & \multicolumn{2}{|l|}{2013} & \multicolumn{2}{|c|}{2014} & \multicolumn{2}{|l|}{2015} & \multicolumn{2}{|c|}{2016} & \multicolumn{2}{|c|}{2017} \\
\hline & $\begin{array}{c}\begin{array}{c}\text { Produção } \\
(t)\end{array} \\
\end{array}$ & $\%$ & $\begin{array}{c}\begin{array}{c}\text { Produçãoo } \\
(t)\end{array} \\
\end{array}$ & $\%$ & \begin{tabular}{|c|}
$\begin{array}{c}\text { Produção } \\
\text { (t) }\end{array}$ \\
\end{tabular} & $\%$ & $\begin{array}{c}\begin{array}{c}\text { Produção } \\
\text { (t) }\end{array} \\
\end{array}$ & $\%$ & $\begin{array}{c}\begin{array}{c}\text { Produção } \\
(\mathrm{t})\end{array} \\
\end{array}$ & $\%$ & \begin{tabular}{|c|}
$\begin{array}{c}\text { Produção } \\
(t)\end{array}$ \\
\end{tabular} & $\%$ & $\begin{array}{c}\begin{array}{c}\text { Produção } \\
(\mathrm{t})\end{array} \\
\end{array}$ & $\%$ \\
\hline Brasil & 42.152 & 100 & 38.805 & 100 & 38.300 & 100 & 37.499 & 100 & 40.643 & 100 & 34.664 & 100 & 26.191 & 100 \\
\hline Acre & 14.035 & 33,30 & 14.088 & 36,3 & 13.599 & 35,51 & 13.684 & 36,49 & 14.038 & 30,1 & 8.742 & 25,22 & 4.790 & 18,29 \\
\hline Amazonas & 14.661 & 34,78 & 10.478 & 27 & 11.785 & 30,77 & 12.901 & 34,4 & 13.983 & 29,98 & 14.945 & 43,11 & 12.786 & 48,82 \\
\hline Rorair & 105 & 0,25 & 112 & 0,29 & 171 & 0,45 & 166 & 0,44 & 155 & 0,33 & 161 & 0,46 & 380 & 1,45 \\
\hline Rond & 3.523 & 8,36 & 1.714 & 4,42 & 1.689 & 4,41 & 1.854 & 4,94 & 1.944 & 4,17 & 2.055 & 5,92 & 1.865 & 7,12 \\
\hline Fard & 7.192 & 17,06 & 10.449 & 26,93 & 9.023 & 23,56 & 6.903 & 18,41 & 7.967 & 17,08 & 6.866 & 19,81 & 4.168 & 15,91 \\
\hline Amapá & 401 & 0,95 & 426 & 1,09 & 438 & 1,14 & 466 & 1,24 & 473 & 1,01 & 489 & 1,41 & 476 & 1,81 \\
\hline & 2.234 & 5,30 & 1.538 & 3,96 & 1.596 & 4,17 & 1.524 & 4,06 & 2.082 & 4,46 & 1.407 & 4,06 & 1.706 & 6,51 \\
\hline
\end{tabular}

Fonte: IBGE (2017), organizado pelos autores.

Atualmente, segundo Homma (2017), além de uma grande demanda no mercado mundial pujante, há um forte crescimento do consumo interno. Esses aspectos mostram a importância econômica da castanha e seu potencial em contribuir para o desenvolvimento e o bem-estar das comunidades extrativistas.

\section{PRODUÇÃO DE CASTANHA-DO-BRASIL NO MUNICÍPIO DE TEFÉ, AM}

No Amazonas, dos 62 municípios existentes, 10 concentram mais de $50 \%$ da produção estadual de castanha: Codajás, Autazes, Beruri, Boca do Acre, Humaitá, Lábrea, Manicoré Tefé e Novo Aripuanã.

O município de Tefé esteve entre os dez maiores produtores do Amazonas, nos últimos sete anos. Sua produção no período de 2010 a 2017 alcançou 5.768 toneladas, o que representou em média 720 toneladas/ano, permanecendo entre o $5^{\circ}$ e $8^{\circ}$ produtor no ranking do estado do Amazonas. A comercialização de castanha-do-brasil, de outros produtos oriundos da floresta, como a borracha, e da agricultura, a farinha de mandioca forma a base do dinamismo econômico do município de Tefé ao longo do tempo. Diariamente o porto da sede do município encontra-se "repleto de barcos de pequeno, médio e grande porte", que têm no extrativismo e na produção de farinha os principais produtos transportados e comercializados (FAULHABER, 1998, p.21).

A importância econômica da cidade de Tefé vai além dos seus limites territoriais. Desde o período colonial, a cidade é "ponto de apoio para as expedições portuguesas que subiam o Solimões, o Juruá, o Jutaí e Japurá, a fim de extraírem produtos vegetais" (OLIVEIRA; SALGADO, 2008, p.25). 
Com relação à produção de castanha-do-brasil no município, os relatos são antigos, remetendo ao século XIX. Rodrigues (2011) aponta as comunidades de Caiambé, Jutica, Marajó, Catuá e o entorno do Lago de Tefé como as principais áreas produtoras da amêndoa do município. No presente artigo, é apresentada a pesquisa realizada nas comunidades Caiambé, Santo Isidoro, Jutica e Marajó. Essas comunidades e sua importância na produção de produtos extrativistas estão presentes em muitos relatos, que comprovam a importância histórica delas para a economia municipal.

Cunha (2008, p.42) aponta que o início da exploração da castanha na comunidade do Jutica data de janeiro de 1904, quando o senhor Paulo Alves Fonseca, proprietário do castanhal, autorizou o senhor José Alves, nordestino, a "começar a explorar castanha, sova, borrachas e peles silvestres". Pessoa (2007), em sua pesquisa, destaca que as comunidades de Caiambé, Jutica, Marajó, Catuá, Lago de Tefé, Caiçara, Uarini e Jauató, como importantes localidades de produção extrativista no século XIX. Esses estudos comprovam o longo processo de exploração dos castanhais na região.

A importância do comércio de produtos extrativistas na manutenção do poder dos comerciantes pode ser comprovada pelo fato de a maioria dos castanhais do município de Tefé serem privados. Um dos exemplos é o da comunidade do Jutica, que pertence à família Cunha, e o da comunidade de Santo Isidoro, que pertenceu ao Senhor Jorge Rezala, que "morreu sem deixar herdeiros" e era "dono de quase todos os castanhais localizados na região do Lago de Tefé" (RODRIGUES, 2011, p.94).

As pesquisas de Cunha (2008), Pessoa (2007) e Rodrigues (2011) confirmam a força e o poder dos comerciantes sobre as comunidades e o controle sobre a produção extrativista. Faulhaber (1987, p.150-151), tendo como base o estudo do Professor Hellion, mostra que há um grande controle da produção e do trabalho do caboclo na comunidade do município, por famílias tradicionais de Tefé.

De acordo com o Prof. Hellion, este grupo consolidou-se a partir da década de quarenta, enriquecendo-se através da "exploração do trabalho caboclo". E acrescenta que existem facções internas aos "trust": "A família Alves vive se digladiando com os Queiroz e os Roberto. A família Retto é aliada da família Roberto. A família Alves é sozinha e tem grande poder econômico. O antigo prefeito, Afonso Alves, é filho do velho Alves. Existem alianças entre as famílias Retto, Queiróz e Roberto. O atual prefeito é Armando Retto. A família Queiróz é mais política. Os Roberto apoiam os Retto, mas não entram na política. A família Castro Vasconcelos é uma família nova, economicamente falando. Era uma família pobre que se projetou na década de setenta, adotando os mesmos métodos de exploração do regatão. Eles foram estendendo o seu poderio, colocando os barcos o rio e fazendo comércio. A partir de 1964, com a preocupação militar 
com a ocupação da Amazônia, gradativamente, Tefé foi se tornando um centro comercial e surgiram novos métodos de enriquecer. A família Castro Vasconcelos se tornou mais ativa e começou a se introduzir no alto comércio. Conseguiu a representação da gasolina e o monopólio da venda do gás. Isto lhe criou condições. Os outros comerciantes estavam viciados naquele processo de explorar o caboclo. Atualmente (os grandes comerciantes de Tefé) não dependem exclusivamente da exploração do regatão. Fazem mais o alto comércio entre Manaus e Tefé. Fazem mais o comércio de atacado".

Com base nas informações coletadas dos extrativistas, atravessadores, comerciantes, produziu-se uma estimativa da produção das quatro comunidades estudadas em 2016. A estimativa mostra que as comunidades do Caiambé, Marajó, Jutica e Santo Isidoro contribuíram com 19,4\% da produção municipal, ou seja, 139,68 das 720 divulgadas pela IBGE (2017). Isso mostra o potencial de produção de castanha das comunidades pesquisadas (Quadro 2).

Quadro 2. Produção de castanha nas comunidades estudadas e a contribuição delas na produção total do município.

\begin{tabular}{|c|c|c|}
\hline & Produção total (t) & \% \\
\hline Município de Tefé & 720 & 100 \\
\hline Comunidades (total) & 139,68 & 19,4 \\
\hline Caiambé & 44,64 & 6,2 \\
\hline Marajó & 34,56 & 4,8 \\
\hline Jutica & 25,20 & 3,5 \\
\hline Santo Isidoro & 35,28 & 4,9 \\
\hline
\end{tabular}

Fonte: IBGE (2017) e pesquisa de campo (2016), organizada pelos autores.

\section{METODOLOGIA}

A pesquisa foi realizada no município de Tefé, AM, na sub-região região Solimões/Jutaí. A população é de 62.230 mil habitantes, dos quais $12 \%$ (7.4676) vivem na zona rural (IBGE, 2016). O município é um importante centro econômico e social do estado do Amazonas.

A pesquisa envolveu quatro comunidades produtoras de castanhado-brasil: Caiambé, Jutica Marajó e Santo Isidoro. O estudo de Balzon (2012, 
p.6) indica que as comunidades escolhidas se encontram em áreas de grande produção de amêndoa no município. ${ }^{7}$

Essas comunidades caracterizam-se por serem fechadas para públicos externos. Para contornar essa barreira buscou-se o apoio de um "indivíduochave", como preconiza Weber (1996), que era o coordenador da comunidade, o qual facilitou o contato e a realização das entrevistas.

Metodologicamente os resultados apresentados neste artigo foram obtidos com base em uma abordagem quantitativa e qualitativa, ou seja, buscouse "colocar o problema qualitativo da maneira mais concreta e realista, isto é, deseja-se desenvolver a qualidade pelo único modo no qual tal desenvolvimento é controlável e mensurável (GRAMSCI, 1995, p.50)". Desta forma, busca-se estabelecer comparações, relações causais e inferir resultados a partir de uma amostra estatística representativa. A pesquisa também classifica-se como exploratória, já que há poucos conhecimentos acumulados sobre a dinâmica socioeconômica das comunidades estudadas (GIL, 2002). A investigação foi antecedida de revisão bibliográfica e coleta de informações com agentes sociais que conhecem o município. Foram entrevistados 31 extrativistas, representando $20 \%$ das pessoas das comunidades. As entrevistas permitiram ter uma visão ampla da dinâmica socioeconômica relacionada à atividade extrativista da castanha-do-brasil. Os entrevistados foram selecionados de forma aleatória.

Os dados coletados foram sistematizados e analisados utilizando-se cálculos estatísticos simples, sistematizados em tabelas e analisados com base na metodologia relacionada ao extrativismo de castanha-do-brasil.

\section{RESULTADOS}

Os dados coletados permitem a identificação de fatores relacionados à estrutura familiar, ao desenvolvimento socioeconômico e produtivo, à organização socioeconômica, à estrutura fundiária e ao acesso a políticas públicas.

\subsection{Fatores relacionados à estrutura familiar dos extrativistas}

A análise das informações coletadas, no seu conjunto, mostra a posição dos extrativistas na estrutura de comercialização de castanha-do-brasil. Traz informações que permitem analisar o futuro das comunidades e a questão sucessória na atividade da coleta da castanha. Evidenciam uma série de problemas a serem enfrentados e permitem projetar a comunidade e seu desenvolvimento futuro.

7 O estudo de Balzon (2012, p.6) mostra que as áreas mais produtivas do município de Tefé são a região da Resex Estadual Catuá/Ipixuna, as comunidades do Jutica, Marajó e Caiambé. 
A coleta de castanha-do-brasil é uma atividade restrita às comunidades extrativistas. Não é uma atividade que atrai outros trabalhadores, buscando oportunidades, ou desloca pessoas da cidade para as áreas de coleta, ou cria trabalho sazonal, como a colheita do café na região do sul de Minas Gerais (Ribeiro, 2015). A coleta é totalmente realizada por comunidades tradicionais, que definem o melhor período e data de coleta.

É possível observar certa autonomia dos extrativistas em relação à castanha. Atualmente, investem no desenvolvimento de culturas anuais e fruteiras, ao invés de coletar castanha, os programas sociais complementam a renda.

A pesquisa mostrou que, ao longo do tempo, ser coletor de castanha não era uma escolha, o filho de extrativista de castanha seria extrativista, e que os filhos sucederiam os pais na atividade. As informações coletadas na pesquisa apontam que $89 \%$ do total dos extrativistas de castanha sucederam os pais na atividade e $11 \%$ sucederam os avós, já que os pais não continuaram o "ofício" do seu genitor. Há uma transmissão de conhecimento por meio da convivência diária na família.

Nos castanhais, em termos tecnológicos, parece que o tempo parou. Não há introdução de novas tecnologias que facilitem o trabalho e a coleta da castanha. O facão e os cestos de cipó continuam sendo os principais acessórios que auxiliam na coleta. A única grande transformação tecnológica que ocorreu nas comunidades e nos castanhais foi a introdução do motor rabeta, ${ }^{8}$ que reduz o tempo de percurso da comunidade para os castanhais, reduzindo também a necessidade de os extrativistas fixarem acampamento nos castanhais no período da coleta, como outrora.

Constatou-se que o número de pessoas da família que trabalham na coleta vem reduzindo ao longo do tempo nas comunidades extrativistas analisadas. Essas famílias, que até algum tempo atrás caracterizavam-se como numerosas, hoje apresentam uma média de 2,5 pessoas por núcleo familiar. Isso evidencia a tendência de redução do tamanho das famílias e, como consequência, redução da mão de obra disponível para o processo de coleta de castanha, que envolve ações como: abrir caminhos na floresta, caminhar coletando, quebrar os "ouriços, " lavar e transportar a produção pelas trilhas da floresta.

Outra tendência nos castanhais é o aumento da idade média das pessoas que desenvolvem a atividade. Há um processo de envelhecimento. A pesquisa

8 O motor rabeta é um motor de baixa potência, normalmente de $5 \mathrm{HP}$, a gasolina, e que é fixado diretamente na popa da canoa, proporcionando arranque, movimento e controle de direção ao navegar em rios, lagos, igarapés, inclusive em locais de água com pouco profundidade. A rabeta possui uma haste que permite elevar a hélice rente à superfície da água. É de fácil adaptação e deslocamento, pesa aproximadamente $6 \mathrm{~kg}$, dependendo do modelo. 
mostrou que $65 \%$ dos extrativistas têm idade superior a 40 anos, que é uma idade considerada elevada para quem trabalhou a vida toda como agricultor e extrativista. Dos extrativistas, $23 \%$ encontram-se na faixa de 30 anos de idade e somente $12 \%$ têm idade inferior a 30 anos. Esses dados apontam que a atividade não está agregando pessoas novas e há tendência do envelhecimento de quem pratica a coleta. Esse envelhecimento é decorrente do êxodo rural de jovens, da redução da taxa de fecundidade e do crescimento da expectativa de vida da população em geral. É possível observar uma predominância masculina nas faixas etárias acima de 50, até os 60 anos de idade, entre os trabalhadores dos castanhais.

Classificando a população por faixas etárias e de gênero, percebe-se que há um equilíbrio em algumas faixas na relação de homens e mulheres: nas faixas de 0 a 4 anos (55\% de mulheres e $45 \%$ de homens), de 5 a 14 anos (54\% mulheres e 46 homens), faixas etárias que ainda possuem alta dependência dos pais; na faixa de 30 a 50 (52\% mulheres e $48 \%$ homens), há uma ligeira predominância feminina, cuja explicação pode estar no fato de que as pessoas do sexo feminino nessa faixa etária conseguem emprego na comunidade, geralmente com professores ou funcionários da escola, como também trabalham nos serviços domésticos de famílias, como diaristas, na própria comunidade e na cidade. No caso da cidade, as pessoas trabalham durante o dia e voltam para dormir em casa, no meio rural. Na faixa de 51 a 60 anos, $40 \%$ são mulheres e $60 \%$ homens, há uma predominância masculina na comunidade. Atribuem-se esses percentuais a migração de mulheres ou jovens para as cidades, ao avanço da idade dos homens que não migraram e que ainda praticam o extrativismo e/ou que já são beneficiados pela aposentadoria.

Em relação à faixa etária de 15 a 29 anos, há uma disparidade entre homens e mulheres, que alcança a porcentagem de $33 \%$ de mulher e $67 \%$ de homens. Essa informação confirma o que é dito pelos comunitários. A causa da disparidade seria a saída das pessoas do sexo feminino dessa faixa etária para estudar ou trabalhar na cidade. Os homens permanecem nas atividades de coleta e agricultura, que exigem força física. É o caso da pesca, o roçado e a coleta de castanha no meio da floresta. A outra discrepância está na faixa etária de mais de 60 anos, em que as mulheres representam $77 \%$ do total e os homens $23 \%$, o que estaria relacionado à expectativa de vida maior das mulheres, portanto maior longevidade decorrente de outros fatores, do maior cuidado com a saúde por parte das mulheres. Esse fenômeno também é observado no Sul e Nordeste do Brasil, onde as aposentadorias e pensões da previdência são "dirigidas a mulheres viúvas, solteiras ou separadas" (MINAYO; COIMBRA Jr. 2002, p.18). Os homens, devido a extenso período de sua vida submetido ao trabalho pesado, às atividades agrícolas, além de falta de autocuidado com a saúde, vivem menos tempo. A análise dessas duas faixas etárias, considerando que a faixa de 30 a 50 anos num relativo equilíbrio entre homens e mulheres, 
evidencia uma tendência de masculinização gradativa da população das comunidades estudadas.

Os dados relacionados a família, composição, gênero, sua relação com a dinâmica produtiva extrativa e agrícola evidenciam a necessidade de introdução de novas tecnologias nos castanhais, com o objetivo de garantir a produção, a melhoria na produtividade do trabalho e o aumento da renda das famílias. Isso tornaria a atividade mais atrativa para os adolescentes e jovens, em termos econômicos e de bem-estar.

\title{
5.2 Fatores relacionados ao desenvolvimento socioeconômico e produtivo
}

\subsubsection{Educação}

Para Vieira Filho e Silveira (2013, p.723), a educação é essencial para "transformar um conhecimento experimental em uma tecnologia superior". Então, a educação é o principal instrumento para superação de problemas de difícil solução.

Em relação à formação dos extrativistas, $17 \%$ são analfabetos, que é quase o dobro da taxa nacional; $48 \%$ concluíram as séries básicas, entre o primeiro e o quinto ano, e $19 \%$ do sexto ao nono ano, $12 \%$ chegaram ao ensino médio, sendo que somente 3\% concluíram essa etapa. Essa situação limita a busca e o uso de novas técnicas, de conhecimento de uma base de cálculos e implementação de técnicas racionais, que exigem o mínimo de domínio sobre elas. Como agravante temos ainda comunidades que possuem escolas transplantadas da cidade para o interior, desenvolvendo uma educação descontextualizada, distante da realidade da dinâmica agrícola, extrativa, rural. Tal aspecto fortalece a concepção de uma educação urbanizada no meio rural. Esse fato distancia, cada vez mais, os jovens de sua realidade. Para Silva et al. (2018, p.25)

\begin{abstract}
A educação por si só não promove o desenvolvimento, mas propicia elementos para isso e permite aos indivíduos acessar recursos disponibilizados em meios de difusão de tecnologias, ter facilidade em formulações e orientações técnicas e alcançar parâmetros mais sólidos de qualificação, que pode desencadear um processo de melhoria de vida individual e comunitário.
\end{abstract}

Os números mostram um alto grau de analfabetismo entre adultos nas comunidades, superior à média do país. A baixa escolaridade interfere no fortalecimento da economia e organização dos comunitários que seria um instrumento para romper o ciclo vicioso da pobreza. 


\subsubsection{Fatores da organização socioeconômica dos extrativistas}

A organização social é um forte instrumento de incidência sobre as esferas governamentais, acesso ao mercado e aquisição de equipamentos e insumos. $\mathrm{Na}$ Amazônia há exemplos como o da Cooperativa Mista Agroextrativista Sardinha (COOPMAS) (SILVA et al., 2015), que possibilitou melhorar a "apropriação da renda pelos extrativistas, através da organização cooperativa, ampliando a rede de acesso aos mercados", a organização como meio de garantir a conservação dos recursos naturais de comunidades tradicionais, como no caso da implantação da Reserva de Desenvolvimento Sustentável (RDS) no Campo da Mangaba, município de Maracanã, no Pará (PINTO; SCHMITZ, 2017), como o caso da Cooperativa Mista dos Trabalhadores Agroextrativistas do Alto Cajarí (COOPERALCA) e da Cooperativa Mista dos Produtores e Extrativistas do Rio Iratapurú (COMARU), que são instrumentos capazes de ampliar a interação com parceiros, como forma de superar dificuldade e potencializar estratégias (RIBEIRO; XIMENES, 2009).

Os casos acima mostram que a organização, assim como o sindicato, a associação, a cooperativa e outras formas de organização, pode possibilitar aos agricultores sair da invisibilidade e serem reconhecidos por outros atores e o poder público, e ajudá-los a superar as condições de injustiça e desrespeito social (HONNETH,2009).

No caso das comunidades de extrativistas de Tefé, há o sindicato e a associação, que são organizações onde os extrativistas estão filiados, porém essa organização não influencia a organização e a comercialização da produção extrativista.

O sindicato é importante para garantia de direitos como aposentadoria, seguro- defeso e outros. As associações locais possuem um papel muito reduzido no processo de desenvolvimento econômico da comunidade. Sussumo e Mendes (2014, p.10) descrevem que na comunidade Santo Isidoro há duas associações: a Associação de Produtores de Cana-de-Açúcar (APROCANSI), que produz "o mel, rapadura, garapa" e que tem a experiência de comercialização para a merenda escolar; e o Sindicato de Pescadores de Tefé (SINDPESCA), que tem realizado cursos de beneficiamento, "a agricultura (cana e mandioca), a pesca e tem se tornado uma das principais fontes de renda das famílias. Em relação à floresta, não há uma relação intensa, o extrativismo animal e vegetal tornou-se esporádico".

Porém, mesmo com essas duas organizações, os extrativistas da comunidade de Santo Isidoro têm um alto percentual de pessoas não filiadas a nenhuma organização $78 \%$, sendo que dos participantes filiados $10 \%$ fazem parte do sindicato e $12 \%$ da associação. Essa conduta está relacionada ao fato de as organizações estarem passando por processos de reorganização.

Na comunidade do Marajó, o índice de não filiados chega a 75\%, e 25\% estão filiados aos sindicatos, principalmente aos dos pescadores e aposentados, 
pela necessidade de acessar o benefício. Jutica possui 33\% que não participam e $67 \%$ de pessoas associadas ao sindicato, grande parte da comunidade que se dedica à pesca artesanal. A comunidade de Caiambé possui $40 \%$ de pessoas associadas ao sindicato, $25 \%$ filiados à associação e $35 \%$ não estão vinculados a nenhuma organização.

Em todas as quatros comunidades pesquisadas, há um índice muito elevado de pessoas que não participam das organizações comunitárias. Fica muito claro também que, quando ocorre a participação, esta é movida por interesses particulares e individuais específicos, como acesso ao seguro-defeso, à aposentadoria ou à comercialização de algum produto agrícola. É o caso da comunidade de Santo Isidoro, cuja associação viabiliza a comercialização dos produtos.

O aspecto negativo, pensando no futuro, é a falta de perspectiva das organizações e dos comunitários em fortalecer as organizações, para que sejam instrumento capaz de impulsionar o desenvolvimento comunitário, com poder de mobilizar os extrativistas, incidir sobre as esferas municipal, estadual e federal para garantir acesso de seus filiados a políticas públicas de crédito, ampliação do serviço de assistência técnica e fortalecimento do processo de produção e comercialização da produção agrícola e dos produtos extraídos da floresta.

Os números mostram que a organização social e econômica é frágil e não é, ainda, um instrumento capaz de promover mudanças socioeconômicas nas comunidades, principalmente relacionadas à produção extrativista. Essa situação fragiliza os extrativistas diante dos comerciantes, que têm maior poder de barganha nas negociações para aquisição da produção.

A fragilidade dos extrativistas frente aos patrões, comerciantes e atravessadores pode ser observada na comercialização, que é feita de modo individual, e a maioria dos compradores adquire o produto diretamente das unidades familiares ou no porto da cidade de Tefé, também de forma individual, onde os atravessadores e comerciantes possuem vantagem sobre os extrativistas. Para se ter ideia da fragilidade na hora da comercialização, $71 \%$ dos extrativistas vendem sua produção na própria comunidade e $29 \%$, no porto da cidade.

O controle sobre a produção dos extrativistas ainda é muito forte nas comunidades. Do total dos entrevistados $45 \%$ recorrem ao adiantamento de dinheiro ou produtos alimentícios dos comerciantes, o que garante a estes últimos terem acesso à produção de forma adiantada. Sobra pouca produção para o extrativista barganhar melhor preço. O comprador/credor faz o preço. Essa negociação é, muitas vezes, realizada sob condições obscuras, sem muita clareza para os extrativistas.

Há um potencial produtivo, do extrativismo e agrícola, que não evolui pela fragilidade organizativa. A falta de acesso a políticas de assistência 
técnica, às tecnologias de produção e estratégia comercial são consequências dessa fragilidade organizativa, que por sua vez se reflete na geração de renda, como pode ser observado na figura 2. A renda da maioria dos 31 agricultores pesquisados não ultrapassa os 40 mil reais ao ano. E se considerar somente a renda oriunda da agricultura e do extrativismo, ela fica abaixo dos 15 mil reais por ano, o que evidencia a importância das rendas não agrícolas (aposentadoria, seguro-defeso e bolsa-família) para grande parte dos extrativistas.

Figura 2. Participação das receitas agrícolas, extrativas e não agrícolas na formação da renda das 31 famílias de agricultores extrativistas - Ano-base 2016.

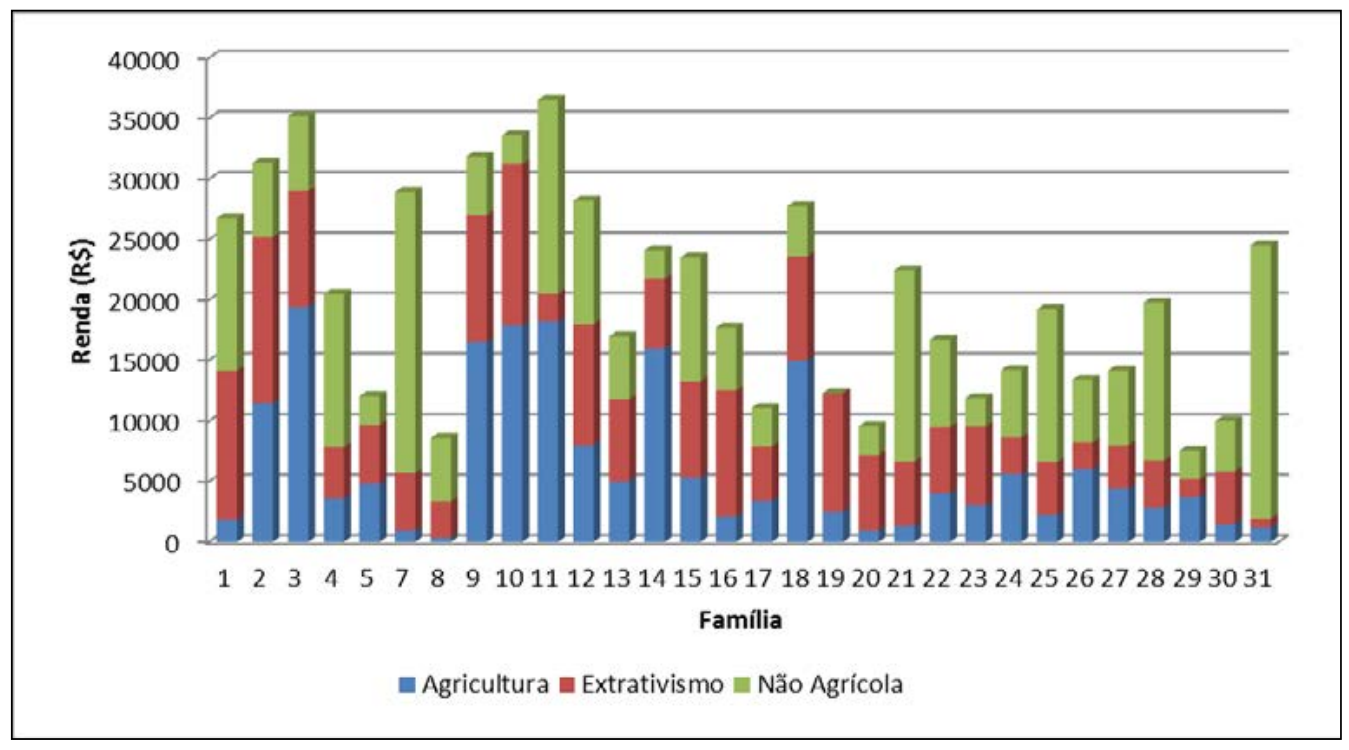

Fonte: Silva et al. (2018, p.21).

A determinação da renda bruta das famílias pesquisadas foi realizada por Silva et al. (2018), com base nos números apresentados no Quadro 3. Nesse exercício, a renda das famílias extrativistas variava de " $R \$ 119,00$ a $R$ \$1.022,00. O intervalo de renda familiar mensal mostra uma situação em que a maioria dos pesquisados ganha até três salários mínimos brutos", rendimento somente alcançado com a soma das "atividades agrícolas, extrativas e das rendas não agrícolas". 
Quadro 3. Renda mensal e per capita, por família, das comunidades pesquisadas em Tefé, AM.

\begin{tabular}{|c|c|c|c|c|c|c|c|}
\hline \multirow[t]{2}{*}{$\mathrm{N}$} & \multirow{2}{*}{ Renda } & \multirow{2}{*}{$\begin{array}{l}\text { Renda } \\
\text { familiar } \\
\text { mensal }\end{array}$} & \multirow{2}{*}{$\begin{array}{l}\text { Número } \\
\text { de pessoas } \\
\text { por família }\end{array}$} & \multirow{2}{*}{$\begin{array}{c}\text { Renda } \\
\text { per capita } \\
\text { familiar } \\
\text { (mensal) }\end{array}$} & \multicolumn{3}{|c|}{$\begin{array}{l}\text { Contribuição das atividades das rendas } \\
\text { agrícolas/extrativistas e não agrícolas }\end{array}$} \\
\hline & & & & & Agricultura & Extrativismo & Não agrícola \\
\hline 1 & $26.773,00$ & $2.231,08$ & 6 & 371,00 & 6,72 & 46,18 & 47,09 \\
\hline 2 & $31.344,00$ & $2.612,00$ & 7 & 373,00 & 36,69 & 43,64 & 19,67 \\
\hline 3 & $35.174,00$ & $2.931,00$ & 9 & 325,00 & 55,21 & 27,26 & 17,52 \\
\hline 4 & $20.458,00$ & $1.704,00$ & 6 & 284,00 & 17,60 & 20,77 & 61,63 \\
\hline 5 & $12.054,00$ & $1.004,50$ & 3 & 334,00 & 39,82 & 40,57 & 19,61 \\
\hline 7 & $28.944,00$ & $2.412,00$ & 3 & 804,00 & 3,11 & 16,58 & 80,31 \\
\hline 8 & $8.599,00$ & 716,00 & 6 & 119,00 & 4,07 & 34,95 & 60,98 \\
\hline 9 & $31.864,00$ & $2.655,00$ & 9 & 295,00 & 51,78 & 32,95 & 15,26 \\
\hline 10 & $33.594,00$ & $2.799,50$ & 3 & 933,00 & 53,22 & 39,74 & 7,04 \\
\hline 11 & $36.508,00$ & $3.042,00$ & 8 & 380,00 & 49,85 & 6,30 & 43,85 \\
\hline 12 & $28.200,00$ & $2.350,00$ & 3 & 783,00 & 28,37 & 35,46 & 36,17 \\
\hline 13 & $16.964,00$ & $1.413,00$ & 8 & 176,00 & 29,47 & 40,08 & 30,44 \\
\hline 14 & $24.114,00$ & $2.009,50$ & 3 & 669,00 & 66,35 & 23,85 & 9,80 \\
\hline 15 & $23.494,00$ & $1.957,00$ & 6 & 326,00 & 22,56 & 33,84 & 43,60 \\
\hline 16 & $17.714,00$ & $1.476,00$ & 2 & 738,00 & 11,86 & 58,99 & 29,15 \\
\hline 17 & $11.100,00$ & 925,00 & 5 & 185,00 & 30,63 & 40,54 & 28,83 \\
\hline 18 & $27.751,00$ & $2.312,00$ & 4 & 578,00 & 54,05 & 30,99 & 14,96 \\
\hline 19 & $12.330,00$ & $1.027,00$ & 3 & 342,00 & 20,28 & 79,72 & \\
\hline 20 & $9.564,00$ & 797,00 & 3 & 265,00 & 9,41 & 65,87 & 24,72 \\
\hline 21 & $22.458,00$ & $1.871,00$ & 4 & 467,00 & 5,79 & 23,82 & 70,39 \\
\hline 22 & $16.700,00$ & $1.391,00$ & 6 & 231,00 & 23,95 & 32,93 & 43,11 \\
\hline 23 & $\begin{array}{r}11.90 \\
4,00 \\
\end{array}$ & 992,00 & 3 & 330,00 & 25,20 & 54,94 & 19,86 \\
\hline 24 & $14.204,00$ & $1.183,00$ & 3 & 395,00 & 39,43 & 21,40 & 39,17 \\
\hline 25 & $19.208,00$ & $1.600,00$ & 2 & 800,00 & 11,45 & 22,91 & 65,64 \\
\hline 26 & $13.394,00$ & $1.116,00$ & 7 & 159,00 & 44,80 & 16,65 & 38,55 \\
\hline 27 & $14.164,00$ & $1.180,00$ & 2 & 590,00 & 31,06 & 25,42 & 43,52 \\
\hline 28 & $19.794,00$ & $1.649,50$ & 4 & 412,00 & 14,40 & 19,70 & 65,90 \\
\hline 29 & $7.564,00$ & 630,00 & 4 & 157,00 & 49,58 & 19,17 & 31,25 \\
\hline 30 & $10.014,00$ & 834,50 & 7 & 119,00 & 14,98 & 43,44 & 41,58 \\
\hline 31 & $24.538,00$ & $2.044,83$ & 2 & $1.022,00$ & 4,89 & 2,97 & 92,13 \\
\hline
\end{tabular}

Fonte: Silva et al. (2018, p.24). 
A formação da renda familiar anual dos extrativistas é decorrente das múltiplas atividades desenvolvidas e dos programas acessados. Entre as atividades extrativas citam-se a pesca, realizada diariamente, a coleta de açaí e de castanha-do-brasil, no período de safra.

Os dados da renda obtida pelos agricultores durante o ano, mostra a grande dificuldade relacionada à produção e comercialização, visando à melhoria de renda. As comunidades extrativistas ainda necessitam percorrer um longo caminho até alcançar o desenvolvimento comunitário e familiar.

\subsubsection{Fatores relacionados à estrutura fundiária e política pública}

As comunidades, com suas limitações socioeconômicas, encontram grandes dificuldades em acessar políticas públicas voltadas a incentivar a produção agrícola e extrativista. Entretanto, muitos dos desafios dessas comunidades estão relacionados a aspectos históricos e à inoperância do estado em garantir as condições e o aparato legal para acessar programas e projetos de desenvolvimento rural.

Um dos primeiros aspectos é a questão fundiária. A maioria das famílias das comunidades ainda não possui titulação da terra em que vivem, já que a maioria dos castanhais ainda se encontra sob a chancela de terras particulares pertencentes a "famílias tradicionais": os castanhais da comunidade do Jutica pertencem à familia Cunha; a de Santo Isidoro, ao senhor Jorge Rezala, que também é dono dos castanhais situados na região do Lago de Tefé. Segundo Rodrigues (2011, p.94), o senhor Rezala morreu sem deixar herdeiros, porém as "comunidades ocupantes" não são reconhecidas como proprietárias, não há titulação. Tal aspecto confirma como a estrutura agrária na região ainda é arcaica. E como é de conhecimento de todos, o documento da terra, a titulação, é condição básica para o acesso de programas e políticas públicas de desenvolvimento, como crédito e outros.

Os extrativistas têm consciência de que sua atividade é realizada em áreas particulares, quando perguntados sobre a situação da área: $44 \%$ respondem que a coleta ocorre em áreas particulares; 33\%, que em áreas devolutas; e 23\% não sabem a situação da área.

A assistência técnica também aparece como fator limitante, seja pública, de ONGs ou privada. Isso é decisivo para que a inovação nos castanhais e na agricultura avancem lentamente. Desta forma, a "coleta da castanha- dobrasil permanece inalterada há séculos, cuja estagnação ocasionou a perda de competitividade do produto brasileiro, exatamente como ocorreu com os seringais em relação aos plantios na Ásia, no passado (SILVA, 2010, p.114) ".

\section{Considerações}

O extrativismo da castanha-do-brasil está na base da formação histórica da sociedade amazônica e é uma importante atividade econômica capaz de 
contribuir de forma decisiva para a conservação da Floresta Amazônica. Infelizmente, a atividade sempre esteve vinculada a intenso processo de exploração das comunidades indígenas, negras e de migrantes nordestinos, que vieram para essa região.

$\mathrm{O}$ estudo mostrou que, em muitas comunidades amazônicas onde a castanha é abundante, existem fatores sociais, econômicos e políticos que limitam o potencial de desenvolvimento das comunidades e das famílias. A castanha poderia se tornar um elemento que contribuiria de forma significativa para a superação do estado de carência material, a pobreza, promovendo o desenvolvimento das famílias e das comunidades.

Grande parte da riqueza que a floresta gera não fica na floresta, não fica com as famílias e comunidades coletoras, vai para os compradores do produto, que vão agregando valor a cada etapa do processamento e multiplicam o valor do produto até chegar aos mercados finais (internos e externos). A organização social do trabalho e a forma de apropriação da riqueza gerada da castanha, da forma como está posta, não promove o desenvolvimento das comunidades.

O envelhecimento da população das comunidades, consequência das menores taxas de natalidade e do êxodo dos jovens que não desejam mais trabalhar na coleta pela insalubridade do trabalho, associado à baixa renda do trabalho, relega a atividade a um plano inferior de importância.

Uma nova forma de organização social, que busque se apropriar da riqueza gerada pelo trabalho, com mediação de instituições representativas dos trabalhadores, e externas às comunidades, é fundamental para romper um ciclo vicioso da pobreza. Essa "nova" organização social precisa estabelecer políticas de mobilização e organização social, agregação e apropriação de valor do produto, capazes de romper as amarras do aviamento e da comercialização atuais, para que parte significativa da riqueza da floresta permaneça na floresta e promova bem-estar.

\section{Referência}

ALMEIDA, J.J. Os Primórdios da Exploração da Castanha-do-Pará. In: XXIII Encontro Estadual de História da ANPUH, Assis (SP). Anais do XXIII Encontro Estadual de História, 2016.

ATLAS DO DESENVOLVIMENTO HUMANO NO BRASIL (Atlas Brasil). Perfil Municipal de Tefé, AM. PNUD, IPEA, Fundação João Pinheiro, 2013.

BALSON. A. T. Diagnóstico do potencial de produção de castanha-do-brasil no Município de Tefé para instalação de uma usina de beneficiamento. - Estudo de viabilidade econômica. Revista Giz, Maio, 2012. 
BECKER, B. K. Síntese do Processo de Ocupação da Amazônia: Lições do passado e desafios do presente. In: BRASIL. Ministério do Meio Ambiente. Causas e dinâmica do desmatamento na Amazônia. Brasília: MMA, 2001.

BRASIL. Plano Nacional de Promoção das Cadeias dos Produtos da Sociobiodiversidade. Brasília: MMA, 2009.

BRASIL. Decreto n. 6.040 de 07 de fevereiro de 2007. Disponível em: <http:/ /www. planalto.gov.br/ccivil_03/_Ato2007-2010/2007/Decreto/D6040.htm>. Acesso em: 10.12.2016.

BRASIL. Ministério do Desenvolvimento Social e Combate à Fome (MDS). Bolsa Família e Cadastro Único no seu município ((Relatório gerado em 13/10/2018).

Disponível em: <http://mds.gov.br/bolsafamilia> Acesso em 12 jun 2018.

BROSE, M. E. Cadeias produtivas sustentáveis no desenvolvimento territorial: a castanha na Bolívia e no Acre, Brasil. Interações, Campo Grande - Mato Grosso do Sul, v. 17, n. 1, p. 77-86, jan./mar. 2016.

CARVALHO, et. al. Fontes de crescimento das exportações de castanha-do-brasil (1970-1988). Documentos 76. 27 p. Belém: EMBRAPA-CPATU, 1993.

FEARNSIDE, P. Extractive Reserves in Brazilian Amazonia. Bioscience, v. 39, 1989.

GIL, A. C. Como elaborar projetos de pesquisa. 4 ed. São Paulo: Altas, 2002.

GOMES, C. V. A. Ciclos econômicos do extrativismo na Amazônia na visão dos viajantes naturalistas. Boletim do Museu Paraense Emílio Goeldi. Ciências Humanas, Belém, v. 13, n. 1, p. 129-146, jan.-abr. 2018.

GRAMSCI, A. Concepção dialética da história. Rio de Janeiro: Civilização Brasileira, 1995.

HONNETH, A. Luta por reconhecimento: a gramática moral dos conflitos sociais. 2 ed. São Paulo: Editora 34, 2009.

IBGE - Instituto Brasileiro de Geografia e Estatística. 12 de setembro de 2016. Consultado em 12 de setembro de 2016

IBGE - INSTITUTO BRASILEIRO DE GEOGRAFIA E ESTATÍSTICA, 2016.

IBGE - INSTITUTO BRASILEIRO DE GEOGRAFIA E ESTATÍSTICA, 2017.

KITAMURA, P. C.; MULLER, C. H. Castanhais nativos de Marabá-PA: fatores de depredação e bases para sua preservação. Documento 30. Belém: Embrapa. p. 1-32. 1984.

MINAYO, M. C. de S.; COIMBRA JUNIOR, C. E. A. Entre a Liberdade e a Dependência: reflexões sobre o fenômeno social do envelhecimento. In: MINAYO, M. 
C. de S.; COIMBRA JUNIOR, C. E. A. Antropologia, saúde e envelhecimento. Rio de Janeiro: Editora Fiocruz, 2002. p. 11-24.

PEREIRA, H. dos S; VINHOTE, M. L. A; ZINGRA, A. F. C.; TAKEDA,W. M. A multifuncionalidade da agricultura familiar no Amazonas: Desafios para a inovação sustentável. Revista Terceira Margem Amazônia, Manaus, v. 1, n. 5, p.59-74, 2015.

PINTO, S. do S. R.; SCHMITZ, H. Mobilização e conflito no processo de criação de uma unidade de conservação no Pará. Raízes, v.37, n. 1, jan-jun/2017.

PORTO, K. S. Impactos Socioambientais do processo de ocupação da orla do município de Tefé/Amazonas - o bairro do Juruá. Dissertação apresentada à Faculdade de Filosofia, Letras e Ciências Humanas da Universidade de São Paulo. 2011.

RIBEIRO, J. N. O trabalhador rural do café e o trabalho sazonal na região sul de Minas Gerais. Anais do VII Jornada internacional de políticas públicas. UFMA, Maranhão. 2015.

RODRIGUES, E. A. Rede urbana do Amazonas: Tefé como cidade média de responsabilidade territorial na calha do Médio Solimões. Dissertação (Mestrado em Geografia) - Universidade Federal do Amazonas, 2011.

SANTILLI, J. Socioambientalismo e Novos Direitos: proteção jurídica à diversidade biológica e cultural. São Paulo: Peirópolis, 2005. $1^{a}$ reimpressão, 2007.

SAWYER, D. Entraves regulatórios de atividades extrativistas na Amazônia: problemas, enfrentamento e soluções. Nota Técnica elaborada para o Centro de Gestão e Estudos Estratégicos (CGEE), com apoio da Secretaria de Assuntos Estratégicos (SAE) da Presidência da República. 2009.

SILVA, L. de J. de S. et. al. Extrativismo: reflexões a partir da realidade socioeconômica das comunidades coletoras de castanha-do-brasil de Tefé, AM. Documentos 141, p. 31. Manaus: Embrapa Amazônia Ocidental, 2018. ISSN 1517-3135.

SILVA, T. M. F. da. A importância da organização dos extrativistas: uma abordagem a partir da comparação das redes estabelecidas em dois municípios produtores de castanha-do-brasil no Estado do Amazonas. Trabalho apresentado no Congresso ALAS, Costa Rica, 2015.

SILVA, S. M. P. Estado e políticas públicas no mercado de castanha-do-brasil no Estado do Acre: uma análise pela abordagem do desenvolvimento local. Revista IDeAS, v. 4, n. especial, p. 103-128, jun./jul. 2010.

SOUSA, W. P. De. A Castanha-da-Amazônia (Bertholletia Excelsa Bonpl.) no contexto dos novos padrões internacionais de qualidade e segurança dos alimentos. Tese apresentada ao Curso de Pós-Graduação em Extensão Rural da Universidade Federal de Santa Maria (UFSM), Rio Grande do Sul 2018. 
SUSSUMO M. V. P.; MENDES, O. L. Dinâmica do espaço agrário no município de Tefé: Reflexões iniciais sobre as comunidades Barreira da Missão, Santa Maria, Santo Isidorio. Anais do VII Congresso Brasileiro de Geógrafos, 2014.

VIEIRA FILHO, J. E. R.; SILVEIRA, J. M. F. J. De. Mudança Tecnológica na Agricultura: uma revisão crítica da literatura e o papel das economias de aprendizado. Revista de Economia e Sociologia Rural, Piracicaba-São Paulo, Vol. 50, No 4, p. 721742, Out/Dez 2012 - Impressa em Janeiro de 2013.

WEBER, R. Relatos de quem colhe relatos: pesquisas em história oral e ciências sociais. Dados. Rio de Janeiro, v. 39, n. 1, 1996. 